ISSN 1984-3372

http://portaldeperiodicos.unisul.br/index.php/EeN/index

\title{
O USO DE TECNOLOGIAS MÓVEIS E A ORIENTAÇÃO EMPREENDEDORA: ESTUDO EM UMA ORGANIZAÇÃO DE CAPITALIZAÇÃO
}

\section{MOBILE TECHNOLOGY USE AND THE ENTREPRENEURIAL ORIENTATION: STUDY IN A CAPITALIZATION COMPANY}

\author{
Aline Carrion Mendieta \\ Bacharel em Administração pela Universidade Nove de Julho \\ Endereço: Rua. Alcântara, 78, Bairro Vila Maria Baixa, Cep: 02110-010. São Paulo, SP, Brasil \\ Telefone: (11) 2209-2613 \\ E-mail: alinecarrion24@gmail.com
}

\section{Cristina Dai Prá Martens}

Pós-doutorado no CERAG/UPMF - Université Pierre Mendès-France

Coordenadora do Programa de Mestrado Profissional em Administração da Universidade Nove de Julho Endereço: Av. Francisco Matarazzo, 612 - Prédio C - 1ํ andar, Barra Funda, CEP:05001-000. São Paulo, SP, Brasil Telefone: (11) 3665-9321

E-mail: cristinadpmartens@gmail.com

\section{Fabio de Oliveira Bento}

Mestrando do PMPA-GP da Universidade Nove de Julho Professor no Instituto Educacional do Estado de São Paulo, IESP Endereço: Rua Delfim Moreira, 40, Centro, CEP: 09015-070, Santo André, SP, Brasil Telefone: (11) 4427-5877

E-mail: fabio.prof02@gmail.com

\section{Fabrício Martins Lacerda}

Mestre em Administração na área de Gestão de Projetos, pelo PMPA-GP da Universidade Nove de Julho Assistente de Diretoria do Conselho Brasileiro de Oftalmologia Endereço: Rua Casa do Ator, 1117 - cj. 21, Vila Olímpia, CEP: 04546-004, São Paulo, SP, Brasil Telefone: (11) 3266-4000

E-mail: fabriciomlacerda@hotmail.com

Artigo recebido em 10/10/2013. Revisado por pares em 02/12/2013. Reformulado em 05/12/2013. Recomendado para publicação em 05/12/2013 por Ademar Dutra (Editor Científico). Publicado em 20/12/2013. Avaliado pelo Sistema double blind review.
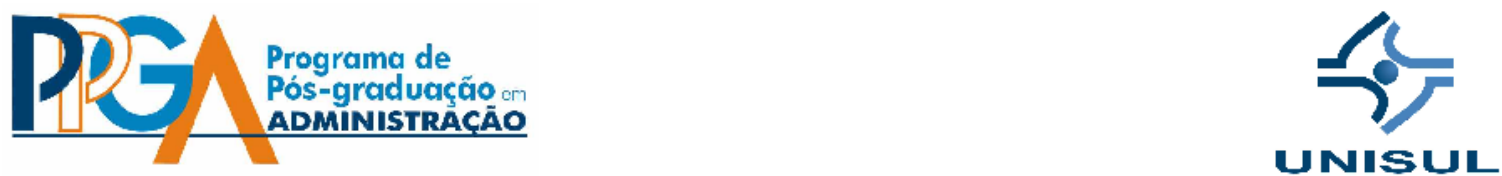


\section{RESUMO}

O uso das Tecnologias de Informação Móveis (TIMS) tem contribuído para as organizações inovarem suas práticas. Estas tecnologias acabam, de certa forma, sendo mediadoras para o empreendedorismo organizacional. A Orientação Empreendedora retrata o empreendedorismo no nível organizacional, permitindo encontrar novas oportunidades de negócios. É caracterizada pelas dimensões inovatividade, assunção de riscos, proatividade, autonomia e agressividade competitiva, podendo sofrer influências de diversos fatores do ambiente, entre eles os tecnológicos. Neste contexto, o objetivo deste estudo é verificar como o uso de TIMS tem efeito nas dimensões da Orientação Empreendedora (OE) de uma organização. A pesquisa foi desenvolvida por meio de estudo de caso de natureza exploratória em uma empresa do segmento de Capitalização. Para a análise dos dados, adotou-se a técnica de análise de conteúdo e a estratégia geral de descrição do caso. Os resultados demonstram que os efeitos do uso de smartphone nas dimensões inovatividade, proatividade, autonomia e agressividade da OE são positivos; já na dimensão assunção de riscos, o uso do smartphone tem auxiliado na prevenção. Pode-se afirmar que o uso de TIMS contribui em parte para a OE da empresa estudada, como também a sua utilização é um facilitador para o comprometimento das pessoas em atividades de inovação. $O$ estudo contribui para a aproximação dos dois temas e pode embasar pesquisas futuras.

Palavras-chave: Orientação Empreendedora; Dimensões da Orientação Empreendedora; Mobilidade Empresarial.

\section{ABSTRACT}

Mobile Information Technologies (MIT) use has contributed to organizations innovate their practices. These technologies have, in a way, being a mediator for organizational entrepreneurship. The entrepreneurial orientation portrays the entrepreneurship at the organizational level, and allows encountering new business opportunities. It is characterizes by innovativeness, risk taking, proactivity, autonomy and competitive aggressiveness dimensions, and may influences from many environmental factors, including technological ones. In this context, the objective in this study is verify how the MIT use presents effects on Entrepreneurial Orientation (EO) dimensions within an organization. The research was developed through case study of exploratory nature in a company from the capitalization segment. For data analysis, the technique of content analysis and the general strategy of case description was adopted. The results show that effects of smartphone use in innovativeness, proactivity, autonomy and aggressiveness of OE dimensions are positive, whereas in risk-taking dimension, the smartphone use has helped in prevention. It is possible argue that MIT uses contribute partially to the company's OE studied, as well as its use is a facilitator for people's commitment with innovation activities. The study contributes for bringing together both themes, and may support future researches.

Keywords: Innovation; Mobile Information Technology; Business Mobility; Entrepreneurial Orientation; Entrepreneurial Orientation Dimensions.

\section{INTRODUÇÃO}


O tema empreendedorismo tem sido foco de vários estudos, contando com uma ampla variedade de conceitos e aplicados em vários contextos (FREITAS et al., 2012). No contexto organizacional, o empreendedorismo é um comportamento que envolve os processos organizacionais, permitindo o encontro de novas oportunidades de negócios (DORNELAS, 2008). Essa afirmativa está alinhada com a abordagem de Lumpkin e Dess (1996) sobre Orientação Empreendedora (OE), que se refere ao comportamento da organização em ser autônoma, tomar atitudes proativas, reagir agressivamente ao mercado, inovar e assumir riscos.

Miller (1983) aponta que o empreendedorismo no contexto organizacional pode sofrer influência de diversos fatores, entre eles variáveis de ambiente, estrutura, estratégia e personalidade do líder, e que isso varia sistemática e logicamente de um tipo de organização para outro. Lumpkin e Dess (1996) corroboram com essas ideias, apontando que as diferenças da OE nas organizações podem ser atribuídas a várias combinações de fatores individuais, organizacionais e ambientais, que influenciam o como e o porquê do empreendedorismo em cada organização.

Dentre os fatores ambientais, encontra-se a tecnologia. Nesse contexto, um tema que tem afetado o modo de trabalho nas organizações é a tecnologia móvel. Segundo Saccol e Reinhard (2007), as Tecnologias de Informação Móveis e Sem Fio (TIMS) vem ocupando um lugar representativo nas organizações pelo motivo de trazerem vantagens, principalmente na interação com os stakeholders e desenvolvimento das atividades dos colaboradores. Esses dispositivos móveis, a exemplo de telefones celulares inteligentes (smartphones), tablets, entre outros, munidos de ferramentas diversas e de acesso à internet, tomam espaço nos ambientes de trabalho, caracterizando a mobilidade (KLEINROCK, 1996; KAKIHARA; SORENSEN, 2001; KALAKOTA; ROBINSON, 2002).

Andriessen e Vartiainen (2006) afirmam que as tecnologias móveis sem fio abrem uma nova perspectiva para produtos, serviços, trabalho e organização, pelo aumento de possibilidades de selecionar mais livremente o local de trabalho, e por permitir uma maior mobilidade do que as tecnologias com fio. Com a possibilidade de acesso irrestrito à informação, independente do local em que se esteja, tais tecnologias têm potencial de contribuir com a autonomia dos colaboradores no contexto profissional, bem como para a proatividade no desenvolvimento das tarefas e identificação de oportunidades, aliado à 
possibilidade de provocar inovações nos processos de trabalhos e no oferecimento de produtos e serviços. Esses e outros aspectos relacionam-se com o empreendedorismo organizacional. Assim, pode-se sugerir que a mobilidade tem potencial de trazer contribuições para o desenvolvimento da orientação empreendedora.

Diante de tal contexto, a seguinte questão motiva a realização deste estudo: como o uso de tecnologias de informação móveis sem fio pode afetar as dimensões da orientação empreendedora da organização? Tem-se como objetivo central verificar como o uso de Tecnologias de Informação Móveis Sem Fio (TIMS) tem efeito nas dimensões da Orientação Empreendedora (OE) de uma organização. Para isso, foi foco de estudo empírico uma empresa do segmento de Capitalização usuária de tecnologias móveis, em que se buscou verificar possíveis efeitos nas dimensões do empreendedorismo organizacional, quais sejam inovatividade, assunção de riscos, proatividade, autonomia e agressividade competitiva.

O artigo está estruturado em cinco seções, partindo desta introdução. A seção seguinte apresenta a fundamentação teórica que embasa a pesquisa. O método do estudo é apresentado na terceira seção. Na sequência, a quarta seção apresenta os resultados obtidos e, por fim, a quinta seção traz as considerações finais da pesquisa.

\section{FUNDAMENTAÇÃO TEÓRICA}

Esta seção faz uma retomada conceitual a respeito da orientação empreendedora e suas dimensões, aborda a mobilidade empresarial propiciada pelo uso de TIMS e os aspectos decorrentes.

\subsection{ORIENTAÇÃO EMPREENDEDORA E SUAS DIMENSÕES}

A orientação empreendedora refere-se a processos, práticas, tomadas de decisões e atividades que guiam a uma nova entrada de negócios, tendo como prospecção agir de maneira autônoma, inovadora, assumir riscos, ser agressivo em relação aos seus concorrentes, e proativo às oportunidades de mercado (LUMPKIN; DESS, 1996). Segundo Covin, Green e Slevin (2006), a OE é considerada como um constructo de estratégia, que 
está inclusa nos resultados de nível organizacional, baseado na gestão, nas crenças e nos comportamentos demonstrados pelos seus gerentes.

Para Miller (1983), Rauch et al. (2009) e Freitas et al. (2012), as empresas que possuem maior OE obtêm diversos benefícios, como o impacto positivo nas medidas de desempenho financeiro e a habilidade em encontrar novas oportunidades. Martens e Freitas (2008) afirmam que a OE pode influenciar positivamente no desempenho das organizações, como também pode ajudar a superar dificuldades de um ambiente pouco dinâmico. Dessa maneira, a própria organização pode criar uma vantagem competitiva.

No início da pesquisa sobre Orientação Empreendedora (OE), Miller (1983) captou três dimensões que definem uma empresa com um comportamento empreendedor, que são inovatividade, assunção de riscos e proatividade, mais conhecida como o constructo unidimensional. A partir de então, vários estudos foram realizados adotando a proposta de Miller (1983). Em 1996, o artigo seminal de Lumpkin e Dess (1996) acrescenta mais duas dimensões à proposta original de Miller como constituintes da $\mathrm{OE}$, a saber: autonomia e agressividade competitiva. Para esses últimos autores, essas dimensões são consideradas aspectos importantes para a orientação empresarial. Essa nova abordagem passa a considerar a OE como um construto multidimensional.

Assim, a abordagem de Lumpkin e Dess (1996) considera a OE como caracterizada por cinco dimensões: (i) inovatividade; (ii) assunção de risco; (iii) proatividade; (iv) autonomia; e, (v) agressividade competitiva. Segundo Rauch et al. (2009), alguns estudiosos argumentam que a OE é mais facilmente identificada por meio da abordagem unidimensional, com a presença necessária das três dimensões. É fato que essa abordagem tem sido mais utilizada na literatura. Contudo, o uso da abordagem multidimensional, também válida, requer que se analisem as dimensões de forma individualizada. Assim, para este estudo, foi adotado o constructo multidimensional por ser mais abrangente para a análise do empreendedorismo no nível organizacional, permitindo uma verificação mais pontual dos efeitos de uso da TIMS nas dimensões. Uma breve descrição sobre cada dimensão é feita a seguir, no intuito de caracterizá-las.

A inovatividade pode ser conceituada como a predisposição da organização em engajar-se em ser participativa, em respaldar ideias novas, processos criativos, novidade, experimentação, de maneira que isso lhe gere resultados em novos produtos, serviços ou 
processos tecnológicos (LUMPKIN; DESS, 1996). Lee e Peterson (2000) reforçam a inovatividade, afirmando que organizações inovadoras apresentam resultados positivos. Para Dosi (1988 apud FREITAS et al., 2012), a palavra inovação está relacionada com pesquisa, descoberta, desenvolvimento, imitação, adoção de novos produtos, processos produtivos, e de novas técnicas organizacionais. Para Wiklund (1999), ter uma postura estratégica inovadora aumenta as chances de uma organização agir primeiro que seus concorrentes em relação ao lançamento de novos produtos, tendo, dessa maneira, maiores oportunidades no mercado. É consenso entre autores a importância da inovação para o empreendedorismo.

A dimensão autonomia refere-se ao indivíduo ou à equipe que tem a liberdade na tomada de decisão sem restrições organizacionais, o indivíduo que tem a independência de trazer novas ideias ou visões para novas oportunidades. (LUMPINK; DESS, 1996). Segundo Miller (1983), organizações mais empreendedoras têm a liderança mais autônoma. Os autores Lumpkin et al. (2009) corroboram que a autonomia é indispensável para a criação de valores empreendedores e para ter uma noção de estratégia empreendedora. O espírito de liberdade e independência é importante para o surgimento de novas criações. Organizações que se desenvolvem em culturas empreendedoras motivam os indivíduos a serem mais autônomos, de tal forma, reforçando a dimensão autonomia (LEE; PERTERSON, 2000).

A assunção de risco representa assumir riscos e fazer investimentos, pode ser vista como um comportamento dos gestores retratado nas ações organizacionais (LUMPKIN; DESS, 1996). Venkatraman (1989) afirma que essa dimensão contribui para tomadas de decisões na alocação de recursos, porque ela reflete o grau de risco na escolha de produtos e mercados.

De acordo com Lumpkin e Dess (1996), o risco depende do contexto em que será aplicado, por exemplo, no contexto de estratégia existem três tipos de risco: aventurar-se no desconhecido, ou seja, investir em "algo" de que não se tem conhecimento; comprometerse em parcela relativamente grande de ativos, ou seja, investir recursos da empresa sem saber qual será o retorno; e, empréstimos altos.

Para Lumpkin e Dess (1996), as organizações com a OE assumem esses riscos no interesse de obter altos retornos de investimento, aproveitando as vantagens do mercado. 
A dimensão proatividade refere-se aos processos que visam à antecipação e ação sobre necessidades futuras, ou seja, a organização age de uma forma mais rápida em inovar e introduzir novos produtos, visando, assim, estar sempre à frente dos concorrentes. (LUMPINK; DESS, 1996). Miller e Friesen (1978) argumentaram que a proatividade da organização seria determinada após uma questão respondida: a organização é capaz de modelar ou criar os seus próprios meios introduzindo produtos novos, técnicas administrativas e outros, ou simplesmente reage ao mercado? De tal forma, a proatividade se enquadra na organização que é a primeira a inovar em relação ao ambiente externo (FERREIRA, 2007). Assim, a inovatividade está relacionada com rápida ação em resposta às oportunidades, antes das mudanças do mercado (FREITAS et al., 2012). Ferreira (2007), que cita Pensore (1959), afirma que os gestores empreendedores veem oportunidades de expansão e, por isso, são importantes para a proatividade da organização.

Por fim, a agressividade competitiva refere-se à forte capacidade de desafiar seus concorrentes, em busca de bom posicionamento no mercado. (LUMPINK; DESS, 1996). Assim, a agressividade competitiva é a tendência que uma organização tem em responder agressivamente aos concorrentes, em respostas às ameaças do mercado, com o desenvolvimento de ações competitivas. (STAMBAUGH et al., 2009; CHEN; HAMBRICK, 1995). Venkatraman (1989) afirma que para ter vantagens no mercado é necessário fazer alocação de recursos de forma rápida e, assim, ganhar dos concorrentes. Portanto, empresas estabelecidas que tendem a ser mais propensas a novos empreendimentos têm uma agressividade competitiva maior.

O Quadro 1 resume as categorias e os elementos das dimensões da orientação empreendedora. 
Quadro 1 - Categorias e Elementos das Dimensões da Orientação Empreendedora

\begin{tabular}{|c|c|c|}
\hline OE & CATEGORIAS & ELEMENTOS \\
\hline \multirow{6}{*}{ 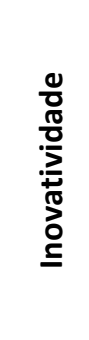 } & - Produtos e Serviços & Novos produtos/ serviços; frequência na mudança em produtos/serviços. \\
\hline & - Processos & Inovação administrativa tecnológica, em produto ou mercado. \\
\hline & - Recursos Financeiros & Investimento em Inovação e P\&D. \\
\hline & - Pessoas & Comprometimento em Inovação dos Recursos Humanos. \\
\hline & - Criatividade & Apoio em novas ideias e experimentos. \\
\hline & - Diferenciação & Iniciativas inovadoras de difícil ação dos competidores. \\
\hline \multirow{4}{*}{ 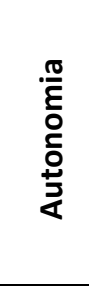 } & -Equipe & Líderes com comportamento autônomo. \\
\hline & - Centralização & Centralização de Liderança. Delegação de Autoridade. \\
\hline & - & Engajar iniciativas empreendedoras. \\
\hline & - Ação Independente & $\begin{array}{l}\text { Pensamentos à ação independente. Cultura que promove ação } \\
\text { independente. }\end{array}$ \\
\hline \multirow{4}{*}{ 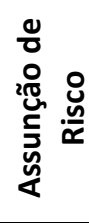 } & - Risco Geral & Organização caracterizada por assumir altos riscos. \\
\hline & - Risco na Decisão & Adotam uma visão pouco conservadora nas decisões. Risco pessoal. \\
\hline & - Risco Financeiro & Postura em Assumir Riscos Financeiros. \\
\hline & - Risco em Negócios & Postura em Assumir Riscos de negócios. \\
\hline \multirow{4}{*}{$\begin{array}{l}\frac{0}{0} \\
\frac{\pi}{0} \\
\frac{0}{2} \\
+0 \\
0 \\
0 \\
0\end{array}$} & $\begin{array}{l}\text { - Monitoramento no } \\
\text { Ambiente }\end{array}$ & $\begin{array}{l}\text { Identificar necessidades, antecipar mudanças, busca de novas } \\
\text { oportunidades. }\end{array}$ \\
\hline & - Atitude de Antecipação & $\begin{array}{l}\text { Primeiro a introduzir novos produtos/serviços, técnicas administrativas } \\
\text { etc. }\end{array}$ \\
\hline & $\begin{array}{l}\text { - Participação e } \\
\text { Resolução de problemas }\end{array}$ & $\begin{array}{l}\text { Procedimentos de controle descentralizados e orienta para busca de } \\
\text { soluções de problemas e novas oportunidades. }\end{array}$ \\
\hline & $\begin{array}{l}\text { - Flexibilidade } \\
\text { Tecnológica }\end{array}$ & $\begin{array}{l}\text { Disponibilidade e acessibilidade de equipamentos para o } \\
\text { desenvolvimento de novos produtos/serviços. }\end{array}$ \\
\hline \multirow{4}{*}{ 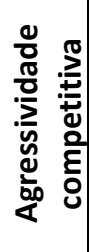 } & - Reação à concorrência & Responder agressivamente aos concorrentes. \\
\hline & - Competição Financeira & Busca posição no mercado à custa de fluxo de caixa ou rentabilidade. \\
\hline & $\begin{array}{l}\text { - Competição em } \\
\text { negócios }\end{array}$ & $\begin{array}{l}\text { Combate tendências que podem ameaçar a sua sobrevivência. Uso de } \\
\text { métodos de competição não convencionais. }\end{array}$ \\
\hline & - Marketing & Gastos agressivos em marketing. \\
\hline
\end{tabular}

Fonte: Adaptado de Freitas, Martens, Boissin, Behr (2012).

Tendo abordado conceitos principais sobre a orientação empreendedora e suas dimensões, a seção a seguir trata sobre a mobilidade empresarial decorrente da adoção e uso de tecnologias móveis, que são consideradas neste estudo como um importante elemento do ambiente organizacional com potencial para afetar o empreendedorismo organizacional.

\subsection{MOBILIDADE PELO USO DE TECNOLOGIAS DE INFORMAÇÃO MÓVEIS SEM FIO (TIMS)}


Mobilidade é a capacidade de levar um dispositivo móvel para qualquer lugar. (KALAKOTA; ROBINSON, 2002). Segundo Vartianinen (2006), a mobilidade tem forte relação com tecnologias sem fio e frequentemente está relacionada ao trabalho móvel. O autor também descreve a mobilidade como a possibilidade de um indivíduo poder executar tarefas em movimento, em qualquer lugar e tempo, desde que use uma Tecnologia de Informação Móvel Sem Fio (TIMS). Alguns exemplos de TIMS são laptops, tablets, telefones celulares, PDAs e smartphones.

Sørensen et al. (2008), por sua vez, definem o conceito de mobilidade empresarial como o fato de as organizações adotarem novas formas de conduzir equipes de trabalho com a TIMS e, assim, contribuir para a melhoria da eficiência e eficácia da informação no trabalho. Para os autores, ao adotarem TIMS, as organizações passam a utilizar o conceito de mobilidade empresarial. Eles salientam que a mobilidade está relacionada à flexibilidade e ao trabalho em movimento, tratando a tecnologia como um aspecto adicional nas práticas do trabalho.

Conforme Manica e Saccol (2009), o uso frequente de dispositivos móveis ajuda na comunicação entre organizações e equipes de trabalhadores externos, que estão geograficamente distantes. Ademais, contribui para que os colaboradores passem a ter contato em tempo real independente do local e tempo (MARQUES; JOÃO, 2003). Autores como Saccol e Reinhard (2005) afirmam que a adoção da tecnologia móvel passa ao cliente uma imagem de organização inovadora. Marques e João (2003) corroboram que os benefícios da utilização de TIMS são o aumento da flexibilidade, a dinâmica competitiva, a melhoria de produtos/serviços e a inovação nos aspectos de negócios.

Sandi e Saccol (2010) concluem que a adoção e o uso de TIMS traz a automação nos processo da organização. Para Saccol e Reinhard (2005), a adoção de TIMS deve estar alinhada ao planejamento estratégico para alcançar seus objetivos, afirmativa corroborada por Tavares et al. (2012), que reforçam que somente após esse alinhamento as organizações podem obter os benefícios esperados das TIMS.

Segundo Machado e Freitas (2009) e Manica e Saccol (2009), a melhor interação entre os stakeholders, a obtenção de vantagem competitiva, a maior agilidade, o aumento de produtividade e os melhores resultados financeiros, são alguns dos principais motivos que levam as organizações a adotarem a TIMS. 
São diversos os benefícios que o uso de TIMS pode proporcionar às organizações, a exemplo da coordenação e do controle de seus processos decisórios. (SACCOL; REINHARD, 2005). Autores como Saccol e Reinhard (2005); Jarvenpaa e Lang (2005); Marques e João (2003); Sandi e Saccol (2010); Manica e Saccol (2009), Mazmanian et al.(2006) apresentam vantagens que a organização obtém no uso de tecnologias móveis, que são resumidas no Quadro 2, a seguir. 
Quadro 2 - Benefícios do uso de TIMS

\begin{tabular}{|c|}
\hline Benefícios \\
\hline 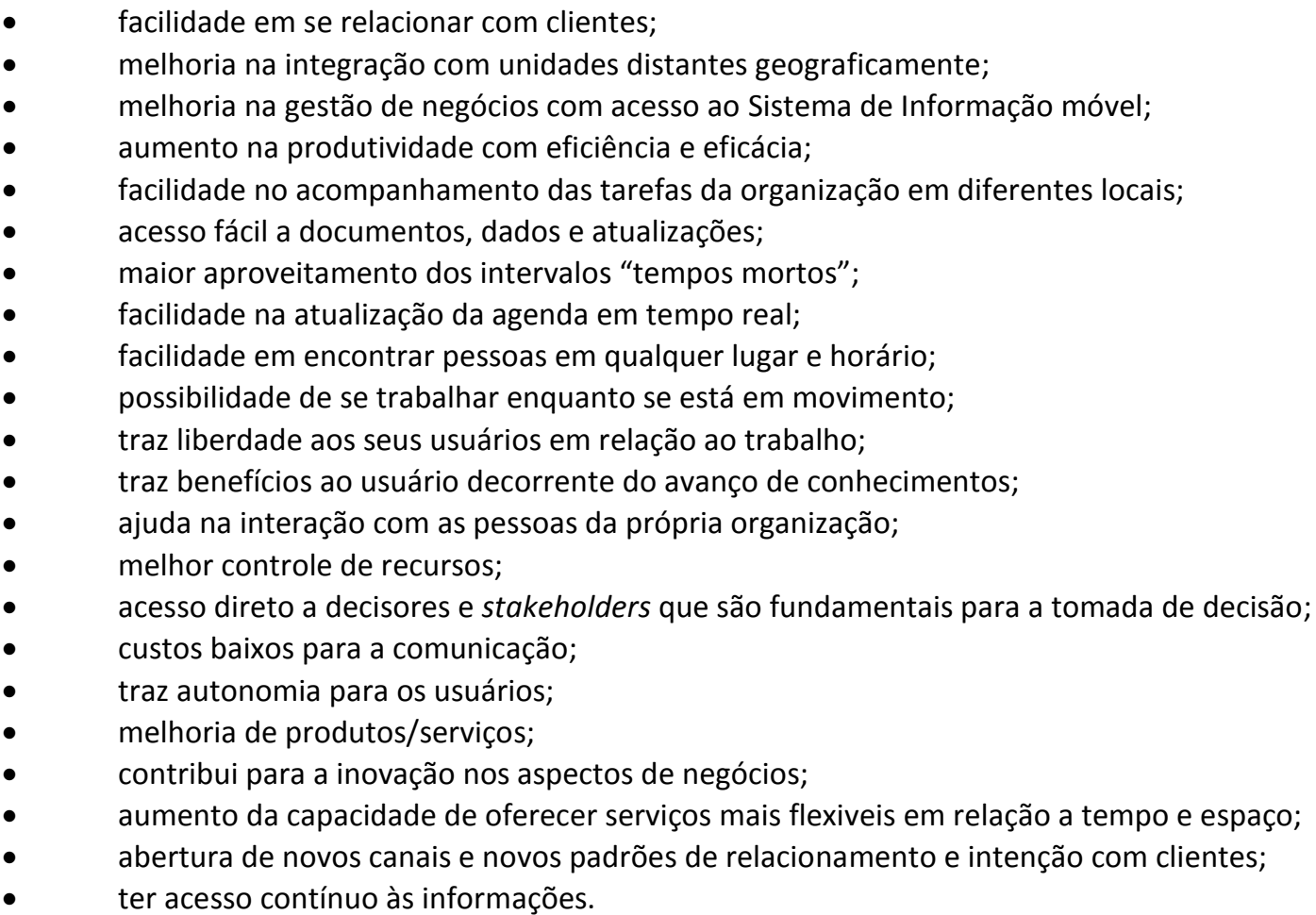 \\
\hline
\end{tabular}

Fonte: Saccol e Reinhard (2005); Mazmanian et al. (2006); Marques e João (2003); Sandi e Saccol (2010); Manica e Saccol (2009); Jarvenpaa e Lang (2005).

Ao analisar tais benefícios, e tendo em vista as dimensões da orientação empreendedora anteriormente abordadas, pode-se observar que alguns têm relação com inovatividade, autonomia, assunção de riscos, proatividade e agressividade competitiva. Alguns exemplos são facilmente identificados: contribuição para a inovação nos aspectos de negócios; melhoria na gestão de negócios com acesso ao sistema de informação móvel; liberdade aos seus usuários em relação ao trabalho; autonomia aos colaboradores; entre outros.

Assim, na sequência deste artigo, apresenta-se o método de pesquisa que foi utilizado para investigar essa potencial relação entre mobilidade e orientação empreendedora.

\section{ABORDAGEM METODOLÓGICA}

O estudo realizado é de natureza exploratória, pois buscou verificar como o uso de Tecnologias de Informação Móveis Sem Fio (TIMS) tem efeito nas dimensões da 
Orientação Empreendedora (OE) de uma organização. Para isso, a estratégia de pesquisa adotada foi o estudo de caso, que é apropriado para responder a questões de pesquisa do tipo "como" e "por que", com foco em fenômeno contemporâneo (YIN, 2005) inserido em contexto empresarial.

O caso escolhido como unidade de análise foi uma organização que comercializa títulos de capitalização e que faz parte de um grupo composto por diversos segmentos empresariais. Essa definição foi motivada pelo fato de a organização ter adotado o uso do telefone celular entre seus funcionários e, atualmente, os consultores de vendas têm utilizado o smartphone para desempenhar suas rotinas de trabalho.

A coleta de dados na empresa envolveu a realização de entrevista com três usuários, principais envolvidos com o uso de TIMS na organização. Assim, foram fonte primária de coleta de dados a realização de entrevistas semiestruturadas composta de questões abertas com o gerente comercial e dois consultores de vendas. Os entrevistados fazem parte do departamento comercial de capitalização e são usuários de TIMS, especialmente o smartphone, em tempo integral. A entrevista semiestruturada trata-se de uma técnica de coleta de dados que é conduzida por meio de um roteiro, porém, permite ao entrevistador acrescentar novas questões (MARTINS; THEÓPHILO, 2009). Fontes de evidências secundárias também foram utilizadas para a coleta de dados, como o website da organização (YIN, 2005).

O roteiro de entrevista semiestruturada foi constituído de questões abertas que abordaram a adoção e o uso de TIMS e seus efeitos no trabalho, bem como elementos das dimensões da orientação empreendedora que tenham relação com a inovação, com comportamento de risco, com ações proativas, com autonomia de pessoas e equipes, e com as ações de competitividade da empresa.

Para a realização da análise dos dados, adotou-se a técnica de análise de conteúdo. (BARDIN, 2010). Para isso, as entrevistas foram gravadas e depois transcritas, constituindo, assim, o conteúdo a ser analisado. Também foi adotada a estratégia geral de descrição do caso, que auxilia no desenvolvimento de uma estrutura analítica descritiva para melhor organizar o estudo de caso (YIN, 2005).

\section{APRESENTAÇÃO E ANÁLISE DOS RESULTADOS}


A organização pesquisada faz parte de uma companhia com diversos segmentos. O segmento que foi estudado é o de venda de títulos de capitalização. A organização tem como missão criar e oferecer aos clientes soluções para suas demandas na utilização de títulos de capitalização, tendo a visão de ser reconhecida no mercado pela criação e por lançamentos de produtos inovadores.

A seguir são apresentados os resultados da verificação do uso de TIMS, com foco especial no uso de smartphone pelos consultores de vendas, e seu efeito nas dimensões da OE na organização.

\subsection{ADOÇÃO E USO DA TIMS NA ORGANIZAÇÃO DE CAPITALIZAÇÃO}

Autores a exemplo de Manica e Saccol (2009) afirmam que as organizações privadas começaram a adotar a TIMS para obter vantagens competitivas e também benefícios financeiros. O gerente comercial relata que a organização adotou o telefone celular há aproximadamente seis anos, e que atualmente seus consultores de vendas utilizam o smartphone como uma importante ferramenta de trabalho. Segundo ele, o uso do smartphone facilitou o contato com clientes, parceiros, como também a verificação dos $e$ mails. Ademais, o seu uso não restringe ao consultor acessar as informações fora do horário de trabalho. $\mathrm{O}$ consultor $\mathrm{X}$ relata que o smartphone é um benefício principalmente por ele atuar na área comercial, pois possibilita acesso aos e-mails, o que antes não era possível, por utilizar somente um telefone celular. Tal fato ficou evidenciado, na seguinte fala: "[...] anteriormente, a gente só conseguia ter acesso aos e-mails uma vez ou duas vezes por semana, então, de certa forma, se tinha uma carência com o cliente com relação a isso. Eles mandavam e-mails e a gente demorava dois, três dias para responder e hoje em dia é mais rápido responder com essa tecnologia". A consultora $\mathrm{Y}$ afirma que os aplicativos como o vivo talk e o wathsapp são facilitadores para se comunicar com os clientes.

Em relação à adoção proativa da organização em fazer uso da tecnologia móvel, o gerente comercial afirmou que há um ano notou que os consultores de vendas dos concorrentes não utilizavam o smartphone, o que the fez perceber que a utilização do dispositivo móvel faria com que seus consultores estivessem tecnologicamente à frente dos 
concorrentes. O consultor $\mathrm{X}$ diz que dos concorrentes que ele conhece, somente $50 \%$ utilizam o smartphone. O mesmo afirma que outro motivo que levou a organização a adotar a TIMS foi a negociação com a operadora considerando custo-benefício, indo ao encontro das vantagens descritas no Quadro 2, referente aos custos baixos de comunicação.

Uma das vantagens que foi ressaltada pelo gerente comercial é a agilidade que o smartphone oferece, conforme identificado nesse trecho de entrevista: "[...] se não tivesse essa tecnologia móvel, seria difícil para os consultores, principalmente para aqueles que não têm condições de sempre estar presente na empresa".

\subsection{EFEITO DA TIMS NAS DIMENSÕES DA ORIENTAÇÃO EMPREENDEDORA}

Nos relatos apresentados pelos entrevistados é possível verificar efeitos do uso da TIMS nas dimensões da OE.

\subsubsection{Inovatividade}

Autores como Marques e João (2003) afirmam que o uso da TIMS pode contribuir para a inovação em negócios. Tavares et al. (2012), ao citarem Schumpeter (1985), corroboram que a inovação é uma vantagem nas estratégias da organização, quando a utilização das tecnologias contribui para o desenvolvimento organizacional, podendo se diferenciar dos concorrentes. Segundo os relatos dos entrevistados, o uso do smartphone favorece nas iniciativas relacionadas à pesquisa e ao desenvolvimento da organização, o que pode se destacar como um fator da dimensão inovatividade.

Os autores Lumpkim e Dess (1996) afirmam que a organização que preza a inovação e respalda novas ideias, processo e outros, pode ser enquadrada como inovadora. Nesse sentido, o gerente comercial afirma que o uso do smartphone facilita na pesquisa de mercado, podendo verificar, por meio dela, imobiliárias que podem ser futuros clientes, e na identificação da região. $\mathrm{O}$ consultor $\mathrm{X}$ diz que o uso do smartphone ajuda na inovação das apresentações de trabalho; segundo o mesmo, às vezes, os clientes solicitam um resumo sobre o que foi apresentado, e o mesmo pode fazê-lo no próprio aparelho ou, ainda, enviar o que já está salvo no smartphone. 
Segundo o gerente comercial, o uso da TIMS possibilitou à organização oferecer novos produtos, o que também é corroborado pelo consultor $X$. No quesito do aumento no marketshare da organização, o gerente comercial afirma que o smartphone contribui em parte, porque para ter uma participação no mercado existem diversos fatores, em que o uso da tecnologia é apenas um deles. Nesse sentido, ele concorda que o uso do smartphone contribui para o aumento da participação no mercado, pois ajuda a divulgar melhor o produto.

Em relação às categorias e aos elementos apresentados por Freitas et al. (2012), observou-se aquelas que são identificadas nos relatos dos entrevistados, apresentadas no Quadro 3.

Quadro 3 - Elementos de Inovatividade identificados na organização pesquisada ELEMENTOS DA INOVATIVIDADE IDENTIFICADOS NO CASO ESTUDADO

Produtos e serviços: Novos produtos/ serviços; frequência na mudança em produtos/serviços.

Processos: Inovação administrativa tecnológica, em produto ou mercado.

Pessoas: Comprometimento em atividades de inovação.

Fonte: Elaboração dos autores (2013).

Observa-se que há um efeito positivo do uso da TIMS em relação à inovatividade, quando o uso do smartphone tem uma parcela de contribuição para a inovação de produtos e agilidade em oferecer informações.

\subsubsection{Autonomia}

Buscando verificar o efeito da TIMS na dimensão autonomia por meio das entrevistas, foi possível identificar que o uso da tecnologia móvel ajuda o consultor externo a tomar decisões. Os autores Lumpkin e Dess (1996) afirmam que a autonomia é uma ação independente de um grupo ou indivíduo. Jarvenpaa e Lang (2005) explanam que o uso de TIMS traz a liberdade para o seu usuário. Mazmanian et al. (2006) corroboram que o uso do smartphone traz a autonomia e flexibilidade para tomar decisões estando fora do local do trabalho. 
Nesse sentido, o gerente comercial esclarece que o uso do smartphone ajuda na resolução de problemas, ao permitir acesso rápido e fácil aos e-mails. O mesmo afirma que, mesmo estando fora do escritório, consegue resolver problemas via e-mails. $\mathrm{O}$ consultor $\mathrm{X}$ relata que quando o cliente tem algum problema, a utilização do smartphone possibilita a sua resolução, o que pode ser identificado também na fala: “[...] apenas com um e-mail você consegue resolver uma questão que poderia demorar mais de quatro dias". A consultora $Y$ corrobora com o uso do smartphone, pois, segundo ela, a resolução de problemas ocorre de forma mais rápida e efetiva junto ao cliente.

O uso do smartphone, segundo o gerente comercial, contribui também para que os consultores trabalhem de maneira autônoma mesmo tendo uma diretriz. Ele comenta, também, que cada consultor tem sua maneira de trabalhar, mas a tecnologia móvel contribuiu para essa autonomia. A consultora $Y$ afirma que, de maneira informal, ela tem essa autonomia. Já o consultor $\mathrm{X}$ comenta que antes eles não tinham acesso a algumas informações e direcionavam o cliente para o departamento administrativo; mas hoje, por utilizarem o smartphone, eles têm acesso a essas informações, o que Ihe traz a sensação de autonomia.

$\mathrm{O}$ consultor $\mathrm{X}$ acredita que o uso do smartphone contribui para a tomada de decisão por conta própria, mas o gerente comercial afirma que isso pode acontecer desde que a decisão seja tomada naquele momento, tornando o uso do smartphone um facilitador, mas fora disso não. $O$ mesmo foi relatado pela consultora $Y$ que, por não ter poder de decisão, não consegue tomar decisões por contra própria, deve antes consultar o gestor. Nesses relatos, pode-se observar que apesar do uso do smartphone, há certo limite em tomar decisões por conta própria, muito por uma diretriz da organização com relação à delegação de autoridade a seus colaboradores.

Em relação às categorias e aos elementos apresentados por Freitas et al. (2012), observou-se as que foram identificadas nos relatos dos entrevistados, apresentadas pelo Quadro 4.

Quadro 4 - Elementos de Autonomia identificados na organização pesquisada ELEMENTOS DA AUTONOMIA IDENTIFICADOS NO CASO ESTUDADO

Equipe: Líderes com comportamento autônomo. 
Centralização: Centralização de Liderança. Delegação de Autoridade.

Fonte: Elaboração dos autores (2013).

Pelos relatos dos entrevistados, apenas duas categorias foram identificados em relação à autonomia que a organização oferece aos seus colaboradores, quando foi questionada a relação do uso de smartphone para esse comportamento.

\subsubsection{Assunção de risco}

A dimensão assunção de risco é um comportamento caracterizado por atitude audaciosa perante o mercado, bem como decisões arriscadas na busca de alto retorno. Segundo Lumpkin e Dess (1996), esse comportamento reflete em enfrentar riscos em negócios desconhecidos, financeiros e outros. Autores como Lunardi et al. (2010) afirmam que deve haver um planejamento antes de adotar uma tecnologia, para que não ocorra desperdício de recursos. Nesse sentido, o gerente comercial afirma que o uso da TIMS, no que se refere à agilidade, auxilia muito na comunicação, principalmente ao receberem comunicados que possam contribuir com atitudes audaciosas. $\mathrm{O}$ consultor $\mathrm{X}$ afirma que $\mathrm{O}$ fato de a organização utilizar a TIMS faz com eles tenham vantagens em relação às outras organizações, tendo em vista que diversos de seus concorrentes não utilizam os smartphones, o que lhes beneficia.

No ponto de vista dos três entrevistados, o uso do smartphone contribui para a avaliação e mensuração de riscos em se tratando de problemas. O gerente comercial comenta que se está fora do escritório ele pode manter contato com seu consultor e tentar ajudá-lo em suas dificuldades. A consultora $Y$ afirma que o avaliar e mensurar os riscos ou problemas por meio da TIMS permite que, de uma maneira rápida, ela consiga resolvê-los.

O consultor $\mathrm{X}$ explana que o uso do smartphone contribui para a comunicação interna com os consultores externos, saber informações sobre vendas do título de capitalização, o que pode ser observado nesse trecho de entrevista:

[...] os estagiários têm a responsabilidade de enviar a avaliação da quantidade de títulos que foram capitalizados por cada consultor e também o montante de valor que foi capitalizado em cada carteira de título, de tal forma que consigo medir o 
que está acontecendo no mercado e ver se os clientes estão se mantendo ou estão se direcionando aos concorrentes. (Entrevista realizada pelos autores, 2013).

Eventualmente, não ter informação detalhada sobre determinados assuntos faz com que a organização corra o risco de perder clientes, mas o uso de dispositivo móvel pode contribuir para situações de incertezas. Nesse sentido, o gerente comercial afirma que quando a decisão deve ser tomada imediatamente, o uso do TIMS pode contribuir favoravelmente. Segundo ele, o ideal mesmo seria realizar uma pesquisa profunda sobre o assunto de incerteza. Contribuindo nesse sentido, o consultor $X$ afirma que o uso da TIMS ajuda nas situações de incertezas, quando está com o cliente. Pelo uso do smartphone, o mesmo consegue direcionar o cliente para a resolução de um problema. A consultora $Y$ afirma que qualquer dúvida que ela tenha, ela acaba enviando um e-mail para seu gestor.

Pelos relatos dos entrevistados, o uso da TIMS contribui para agilidade na tomada de decisões como o consultor X fala: "Sim, isso contribui bastante, principalmente na agilidade da informação". Pelo relato dos entrevistados, observa-se que há certo cuidado em relação a correr risco, não havendo uma postura de assumir riscos, mas sim mais voltada para a informação preventiva.

Em relação às categorias e aos elementos apresentados por Freitas et al. (2012), eles não foram observados nas entrevistas. Contudo, ficou claro que o rápido e irrestrito acesso a contribui para a prevenção de riscos, no sentido de monitorar o andamento das vendas e potencial risco de queda ou de movimentação de clientes para a concorrência.

\subsubsection{Proatividade}

Segundo Lumpink e Dess (1996), uma empresa pode ser considerada com proatividade quando ela tende a agir de forma mais rápida, a inovar e introduzir novos produtos, visando estar sempre à frente dos concorrentes. Nesse sentido, o gerente comercial e os consultores de vendas comentam que o uso do smartphone contribui para que se iniciem ações no mercado, principalmente pela agilidade.

O gerente comercial afirma que $o$ uso do smartphone auxilia no compartilhamento das informações com sua equipe, dando o seguinte exemplo: 
[...] às vezes eu estou na rua e de repente vejo uma oportunidade de negócio, eu acho interessante e compartilho com os demais [...] eu trabalho com a forma de capitalização, com anúncios, placas, posso ver um determinado parceiro que pode ser um cliente potencial para a organização, na mesma hora consigo passar as informações. (Entrevista realizada pelos autores, 2013).

$\mathrm{O}$ consultor $\mathrm{X}$ diz que ter o acesso à internet por 24 horas ajuda a identificar novas oportunidades que podem ser essenciais para a organização, podendo, assim, diferenciar-se dos concorrentes. Outro exemplo é apresentado pela consultora Y: ela afirma que os clientes, de maneira automática, deixam recados ou e-mails para entrar em contato novamente, podendo ser considerado como uma oportunidade ao retornar o contato com o cliente.

A observação para o ambiente externo é um dos fatores para a proatividade da organização. Nesse sentido, o consultor X afirma que o uso do smartphone contribui para o monitoramento do ambiente, quando se trata de clientes, concorrentes e oportunidades de negócios, tendo como vantagem a comunicação rápida. Já o gerente comercial afirma que são diversos os fatores que contribuem para o monitoramento do ambiente, mas o uso de TIMS está entre eles.

Além disso, o gerente comercial afirma que quando a organização vai tomar uma decisão sobre alguma informação, eles se preocupam com pesquisa e análise de mercado, para que possam melhor desenvolver o produto. Nesse sentido, o uso do smartphone contribui para a antecipação da identificação de oportunidades. $\mathrm{O}$ consultor $\mathrm{X}$ corrobora com a afirmação, na seguinte fala: "[...] a gente sempre recebe informações de agências, seguros, cobertura de seguros, então posso dizer que ficamos com uma plataforma sobre o setor atualizado [...] eles sempre passam matérias sobre pesquisa de mercado, oportunidades".

O consultor $\mathrm{X}$ completa que antes eles não tinham um fácil acesso a essas informações, o que agora é possível pelo smartphone. A consultora $Y$ concorda com as afirmações dos outros entrevistados, e conclui que o acesso à informação permite que ela entre nos sites dos concorrentes e fique a par das novidades que foram lançadas.

Em relação às categorias e aos elementos apresentados por Freitas et al. (2012), as que foram observadas nos relatos dos entrevistados são apresentadas no Quadro 5. 
Quadro 5 - Elementos de Proatividade identificados na organização pesquisada

\begin{tabular}{|l|}
\hline \multicolumn{1}{|c|}{ ELEMENTOS DA PROATIVIDADE IDENTIFICADOS NO CASO ESTUDADO } \\
\hline Monitoramento no ambiente: Identificar necessidades, antecipar mudanças, busca de novas oportunidades. \\
\hline Atitude de antecipação: Primeiro a introduzir novos produtos/serviços, técnicas administrativas etc. \\
\hline $\begin{array}{l}\text { Participação e resolução de problemas: Procedimentos de controle descentralizados, orientados para busca } \\
\text { de soluções de problemas e novas oportunidades. }\end{array}$ \\
\hline Flexibilidade tecnológica: Disponibilidade e acessibilidade de equipamentos para o desenvolvimento de \\
novos produtos/serviços.
\end{tabular}

Fonte: Elaboração dos autores (2013).

Nessa dimensão, pode-se observar que o uso do smartphone contribui para que a organização desenvolva sua proatividade, visto que a utilização do smartphone contribui de forma positiva nas categorias apresentadas por Freitas et al. (2012).

\subsubsection{Agressividade competitiva}

A agressividade competitiva, segundo Lumpkin e Dess (1996), é a capacidade de direta ou intensamente desafiar seus concorrentes, para conseguir uma boa posição no mercado. Relacionando com a tecnologia móvel, o gerente comercial afirma que o smartphone é uma ferramenta importante para a competitividade, porque se os consultores não tivessem esse aparelho, eles teriam dificuldade em realizar suas tarefas e também para contatar com os clientes.

O consultor $X$ afirma que a utilização do smartphone contribui para a agilidade no processo de distribuição de informações, principalmente quando se trata de clientes. Ele também afirma que existe a forma de personalizar alguns materiais de acordo com a preferência do cliente, conforme identificado nesse trecho de entrevista: "[...] às vezes o cliente fala 'gostaria que você formalizasse o e-mail de certa forma, nesse sentido para que eu possa encaminhar para um terceiro cliente, proprietário de imóvel, assim a gente consegue imediatamente fazer isso". Identificou-se, também, nas falas dos entrevistados, que pela agilidade que a tecnologia móvel oferece, pode-se reagir agressivamente às ações da concorrência.

Para o gerente comercial, a TIMS contribui para a identificação de informações dos concorrentes em relação aos produtos que eles oferecem, fazendo com que isso os Revista Eletrônica de Estratégia \& Negócios, Florianópolis, v.6, n.3, set./dez.2013 
ajude na melhoria da organização. No mesmo sentido, o consultor $X$ afirma que algumas informações dos concorrentes podem ser identificadas pelo acesso à internet, o relacionamento com parceiros facilita também na identificação de novos produtos que foram lançados pelos concorrentes, sendo identificado na fala do consultor: "[...] o concorrente lançou um produto recentemente, praticamente idêntico ao nosso, com alguns diferencias, alguns parceiros nossos passaram o guia operacional do produto para nós, esse guia operacional foi passado por e-mail, sendo que ele não é disponibilizado na internet".

Nesse sentido, pode-se observar que o contato com os parceiros e o uso de TIMS contribui para a competitividade da organização. Ademais, a empresa, por meio dessas informações, consegue aperfeiçoar o produto ou alterá-lo de maneira que possa oferecer a mais para o cliente.

$\mathrm{O}$ consultor $\mathrm{X}$ afirma que o acesso à internet pelo smartphone ajuda a analisar $\mathrm{e}$ conhecer melhor os concorrentes e, assim, possibilita realizar um benchmarking competitivo. Segundo a consultora $\mathrm{Y}$, existem diversas maneiras de marketing. Ela afirma que a empresa utiliza jornais, parceiros que divulgam a empresa, as telas de informações do metrô e outros. O consultor $\mathrm{X}$ afirma que o uso de TIMS ajudou no marketing da organização porque o uso da internet é um pilar para a divulgação das campanhas.

Assim, o Quadro 6 demonstra as categorias e os elementos que têm relação com os relatos dos entrevistados, na questão da utilização do smartphone em responder agressivamente aos concorrentes. Pode-se observar que há um efeito positivo na utilização do smartphone para a necessidade de reação.

Quadro 6 - Elementos de Agressividade Competitiva identificados na organização pesquisada

\begin{tabular}{l}
\hline \multicolumn{1}{|c|}{ ELEMENTOS DA AGRESSIVIDADE COMPETITIVA IDENTIFICADOS NO CASO ESTUDADO } \\
\hline Reação à concorrência: Responder agressivamente aos concorrentes. \\
\hline Competição em negócios: Combate tendências que podem ameaçar a sua sobrevivência. Uso de métodos de \\
competição não convencionais. \\
\hline Marketing: Gastos agressivos em marketing.
\end{tabular}

Fonte: Elaboração dos autores (2013).

A seguir, são apresentadas as considerações finais do estudo. 


\section{CONSIDERAÇÕES FINAIS: O USO DE TIMS E A ORIENTAÇÃO EMPREENDEDORA}

A Orientação Empreendedora e a Tecnologia de Informação Móvel são temas que estão sendo muito estudados, visto que, atualmente, as organizações procuram manter uma visão empreendedora para alcançar objetivos satisfatórios. Nesse ponto, o uso de TIMS tem contribuído sobremaneira para as organizações. Essas tecnologias acabam sendo um mediador que contribui para a postura empreendedora da organização.

O presente artigo teve como objetivo central verificar como o uso de Tecnologias de Informação Móveis Sem Fio (TIMS) tem efeito nas dimensões da Orientação Empreendedora (OE) de uma organização. Foi possível verificar efeitos positivos em decorrência do uso de smartphone nas dimensões inovatividade, proatividade, autonomia e agressividade. No que se refere à assunção de riscos, não foi percebida uma contribuição para o desenvolvimento desse comportamento, mas sim para a prevenção de riscos, o que de certa forma também é importante no contexto de empreendedorismo. Assim, pode-se afirmar que o uso da TIMS contribui em parte para o desenvolvimento da orientação empreendedora na empresa estudada, como também a sua utilização é um facilitador para a comunicação entre gestor e equipe.

Na dimensão inovatividade, foi possível verificar que o uso de TIMS contribui para essa dimensão, pois os entrevistados relatam que ocorreram mudanças em produtos e processos organizacionais devido à utilização de smartphones.

Em se tratando da dimensão proatividade, o uso de TIMS contribui para o monitoramento do ambiente, visto que há um fácil acesso às informações, sendo possível a antecipação de novos produtos, como também o uso do smartphone contribui para a participação da equipe e na resolução de problemas (via e-mails). A organização se preocupou em fornecer o smartphone para que seus profissionais conseguissem conectar-se diariamente e, principalmente, ficassem atentos às possíveis oportunidades de mercado.

$\mathrm{Na}$ dimensão autonomia, foi possível observar que o gerente comercial e a consultora $\mathrm{Y}$ conseguiram identificar que o uso da TIMS é um mediador de comunicação entre gestor e equipe, podendo, assim, contribuir de certa forma para a autonomia dos usuários. Porém, deixam claro que a autonomia dos colaboradores é relativa, pois há decisões que devem ser tomadas após a consulta e aprovação do seu superior imediato. 
$\mathrm{Na}$ agressividade competitiva, a organização tem certa contribuiç̧ão da TIMS em relação às informações que podem ser adquiridas por meio dela, bem como a identificação de novos produtos fornecidos pelos concorrentes, o que permite à organização responder rapidamente aos lançamentos dos concorrentes.

O receio da organização em assumir risco está relacionado à necessidade de se obter um maior volume de informações antes de tomar uma decisão, e, nesse caso, a organização não possui categorias que lhe enquadrem na dimensão assunção de risco. Contudo, a TIMS contribui para o acesso a informações que auxiliem na prevenção de potenciais riscos.

Por fim, o presente estudo contribui para a academia pela aproximação desses dois temas, com resultados sobre a relação entre o uso de TIMS e a orientação empreendedora. Para a prática organizacional, o estudo traz contribuições à medida que gestores podem identificar nas práticas relatadas neste estudo ações propiciadas pelo smartphone que contribuem para as dimensões da OE em um contexto específico de uma organização.

Como limitação destaca-se o fato de se tratar de estudo de caso único, que não pode ser levado à generalização, mas pode ser considerado como um primeiro passo para futuras pesquisas que relacionam os dois temas. Recomenda-se a realização de estudo de abordagem quantitativa que vise verificar os efeitos das TIMS sobre a orientação empreendedora em uma amostra representativa de organizações. Também é recomendada a realização de estudo de caso múltiplo, no intuito de compreender essa realidade em diferentes contextos organizacionais.

\section{REFERÊNCIAS}

ANDRIESSEN, E; VARTIAINEN, M. Emerging Mobile Virtual Work. In: ANDRIESSEN, E.; VAARTIAINEN, M. (Eds). Mobile Virtual Work: A New Paradigm? Heidelberg: Springer, 2006.

BARDIN, L. Análise de Conteúdo. 5. ed. Lisboa/Portugal: Edições 70, 2010.

CHEN, M. J.; HAMBRICK, D. C. Speed, stealth, and selective attack: how small firms differ from large firms in competitive behaviour. The Academy of Management Journal, United States, v. 38, n. 2, p. 453-482, Apr. 1995. 
COVIN, J.G.; GREEN, K.M.; SLEVIN, D.P. Strategic process effects on the entrepreneurial orientation-sales growth rate relationship. Entrepreneurship: Theory \& Practice, United States, v.30, n.1, p.57-82, Jan. 2006.DORNELAS, J. C. A. Empreendedorismo Corporativo. 2. ed. Rio de Janeiro: Elsevier, 2008.

FERREIRA, J. J. M. A orientação estratégica empreendedora como determinante de crescimento das pequenas empresas da indústria transformadora: o caso português.

Panorama Socioeconômico, Ano 25, n. 34, p. 34-47 Janeiro-Julho 2007.

FREITAS, H.; MARTENS, C. D. P.; BOISSIN, J. P.; BEHR, A. Elementos para guiar ações visando à orientação empreendedora em organizações de software. Revista de Administração, São Paulo, v. 47, n. 2, p. 163-179. abr./mai./jun. 2012.

JARVENPAA, S.; LANG, K. Managing the Paradoxes of Mobile Technology. Information Systems Management, v. 22, n. 4, p. 7-23, 2005.

KAKIHARA, M.; SORENSEN, C. Expanding the 'Mobility' Concept. ACM SIGGROUP Bulletin, $n$. 22, p. 33-37, 2001.

KALAKOTA, R.; ROBINSON, M. M-business: tecnologia móvel e estratégia de negócios. Porto Alegre: Bookman, 2002.

KLEINROCK, L. Nomadicity: Anytime, anywhere in a disconnected world. Mobile Networks and Applications, p. 351-357, 1996.

LEE, S. M.; PETERSON, S. J. Culture, Entrepreneurial orientation, and global competitiveness. Journal of World Business, v. 35, n. 4, p. 401-416, 2000.

LUMPKIN, G. T.; COGLISER, C. C.; SCHNEIDER, D. R. Understanding and measuring autonomy: an entrepreneurial orientation perspective. Entrepreneurship: Theory \& Practice, United States, v. 33, n. 1, p. 47-69, Jan. 2009.

LUMPKIN, G. T.; DESS, G. Clarifying the entrepreneurial orientation construct and linking it to performance. The Academic of Management Review, v. 21, n. 1, p. 135-172, January 1996.

LUNARDI, G. L.; DOLCI, P. C.; MAÇADA, A. C. G. Adoção de tecnologia de informação e seu impacto no desempenho organizacional: um estudo realizado com micro e pequenas empresas. Revista de Administração, São Paulo, v. 45, n. 1, p. 05-17, Jan./Fev./Mar. 2010.

MACHADO, C. B.; FREITAS, H. Planejamento de Iniciativas de Adoção de Tecnologias Móveis. GEPROS. Gestão da Produção, Operações e Sistemas. Ano 4, n. 1, p. 101-115, 2009.

MANICA, A.; SACCOL, A. I. C. Z. Avaliação dos resultados de adoção de tecnologias da informação móveis e sem fio (TIMS): o caso IBGE - CENSO 2007. In: ENANPAD, 33, 2009, São Paulo. Anais. São Paulo: Anpad, 2009. 
MARQUES, E. V.; JOÃO, B. N. Mobilidade: uma investigação de uso por executivos brasileiros. In: ENANPAD, 27으, 2003, Atibaia. Anais. Atibaia: Anpad, 2003.

MARTENS, C. D .P.; FREITAS, H. Orientação empreendedora nas organizações e a busca de sua facilitação. Revista Gestão.Org, v. 6, n. 1, p. 90-108, 2008.

MARTINS, G. A.; THEÓPHILO, C. R. Metodologia da Investigação Científica para Ciências Sociais Aplicadas. 2. ed. São Paulo: Atlas, 2009.

MAZMANIAN, M.; ORLIKOWSKI, W. J.; YATES, J. CrackBerrys: Exploring the Social Implications of Ubiquitous Wireless Email Devices. Conference Paper for EGOS, 2006.

MELLO, Sergio C. B.; LEÃO, André L. M. S. Compreendendo a Orientação Empreendedora de Empresas de Alta Tecnologia. In: SOUZA, Eda C. L.; GUIMARÃES, Tomás A. (orgs.).

Empreendedorismo Além do Plano de Negócios. São Paulo: Atlas, 2005.

MILLER, D. The Correlates of entrepreneurship in three types of firms. Management Science, v. 29, n. 7, p. 770-791, 1983.

MILLER, D.; FRIESEN, P. H. Innovation in conservative and entrepreneurial firms: two models of strategic momentum. Strategic Management Journal, v. 3, n. 1, p. 1-26, jan./mar. 1982.

MILLER, Danny; FRIESEN, P. H. Archetypes of strategy formulation. Management Science, v. 24, n. 9, p. 921-933, May 1978.

RAUCH, A.; WIKLUND, J.; LUMPKIN, G. T.; FRESE M. Entrepreneurial Orientation and Business Performance: An Assessment of Past Research and Suggestions for the Future.

Entrepreneurship Theory and Practice, v. 33, n. 3, p. 761-787, mai.2009.

SACCOL, A. I. C. Z.; REINHARD, N. Processo de Adoção e Decorrências da Utilização de Tecnologias de Informação Móveis e Sem Fio no Contexto Organizacional. In: ENANPAD, 29으, 2005, Anais... Brasília/DF: Anpad 2005.

SACCOL, A. I. C. Z.; REINHARD, N. Tecnologias de Informação Móveis, Sem Fio e Ubíquas: Definição, Estado da Arte e Oportunidades de Pesquisa, Revista de Administração Contemporânea, v. 11, n. 4, Curitiba, out./dez. 2007.

SANDI, L. B.; SACCOL, A. I. C. Z. Sobrecarga de informações geradas pela adoção de tecnologias da informação móveis e sem fio e suas decorrências para profissionais de vendas. Revista Eletrônica de Sistemas de Informação, v. 9, n. 2, artigo 2. Doi:10.5329/RESI. 2010.

SØRENSEN, C.; AL-TAITOON, A.; KIETZMANN J.; PICA, D.; WIREDU, G.; ELALUFCALDERWOOD, S.; BOATENG, K.; KAKIHARA, M.; GIBSON, D. Exploring enterprise mobility: Lessons from the Field. Information Knowledge Systems Management, p. 243-271, 2008. 
STAMBAUGH, J.; LUMPKIN, G. T.; BRIGHAM, K.; COGLISER, C. What makes some firms more competitively aggressive than others? Evidence from the banking industry. In: Academy of Management Proceedings, p. 1-6, 6p, 2009.

TAVARES, E.; LUCAS, C. C.; DIALO, M. F.; LEO, P. Y.; MONNOYER, M. C.; PHILIPPE, J. A Influência do Uso de Tecnologias Móveis na Inovação em Serviços. In: ENANPAD, 36으, 2012, Rio de Janeiro. Anais... Rio de Janeiro/RJ: Anpad 2012.

VARTIANINEN, M. Mobile Virtual Work - Concepts, Outcomes and Challenges. In: E. ANDRIESSEN, M. VARTIAINEN (Eds.) Mobile Virtual Work: A New Paradigm? Heidelberg: Springer, p. 14, 2006.

VENKATRAMAN, N. Strategic orientation of business enterprises: the construct, dimensionality and measurement. Management Science, Baltimore, v. 35, n. 8, p. 942-962, Ago. 1989.

WIKLUND, J. The sustainability of the entrepreneurial orientation-performance relationship. Entrepreneurship: Theory \& Practice, Oxford, v. 24, n. 1, p. 37-48, Winter 1999.

YIN, R. K. Estudo de Caso: Planejamentos e Métodos. 3. ed. São Paulo: Bookman, 2005. 